\title{
Factors contributing to maternal mortality in relatively resource-endowed urban contexts of developing countries: the case of Nairobi, Kenya
}

\author{
Francis Obare ${ }^{1}$, Wilson Liambila ${ }^{1}$, Dan Okoro ${ }^{2}$, Robert Ayisi ${ }^{3}$, and Samuel Ochola ${ }^{3}$ \\ ${ }^{1}$ Population Council, Nairobi, Kenya \\ UNFPA, Nairobi, Kenya \\ ${ }^{3}$ Nairobi City County, Kenya \\ fonyango@popcouncil.org
}

\begin{abstract}
This paper examines factors contributing to maternal mortality in Nairobi County of Kenya. Data are from a study that involved a review of 93 records of maternal deaths at health facilities as well as verbal and social autopsy interviews with 7I caregivers of women who died of maternal-related causes in the community. Results showed that most maternal deaths occurred to women who were young, married, with low levels of education and those having at least two births. In addition, maternal deaths in the County were mostly due to poor health-seeking behaviour, delays at the household level in seeking care, poor referral mechanisms between facilities, poor provider attitudes, and lack of skilled human resources. The findings suggest that programs aimed at improving maternal health in the County need to focus on empowering households to recognize danger signs early, improving referral mechanisms, and enhancing the capacity of providers to offer quality services.
\end{abstract}

Keywords: Maternal mortality; contributing factors; urban contexts; developing countries; Kenya

\section{Résumé}

Ce papier examine les facteurs qui contribuent à la mortalité maternelle dans le comté de Nairobi au Kenya. Les données proviennent d'une étude qui a procédé à une revue de 93 dossiers de décès maternels survenus dans les établissements de santé ainsi que sur des entretiens d'autopsie verbale et sociale auprès de $7 \mathrm{l}$ personnels soignant ayant traité des femmes qui sont mortes de causes maternelles au sein de la communauté. Les résultats ont montré que la plupart des décès maternels sont survenus chez des femmes jeunes, mariées, avec de faibles niveaux d'éducation et ayant eu au moins deux naissances. En outre, les décès maternels dans le comté étaient pour la plupart liés à des comportements inadéquats de reherche de soins, au retard dans la recherche de soins au niveau des ménages, au système d'orientation-recours inefficaces entre les établissements, aux attitudes inappropriées des prestataires, et au manque de ressources humaines qualifiées. Les résultats suggèrent que les programmes visant à améliorer la santé maternelle dans le comté devraient se focaliser sur la capacitation des des ménages à reconnaître de façon précoce les signes de dangere, sur l'amélioration des mécanismes de référence et le renforcement des prestataires à offrir des services de qualité.

Mots-clés: Mortalité maternelle; facteurs contributifs; contextes urbains; pays en voie de développement;

Kenya

\footnotetext{
'Address for correspondence: Francis Obare, Population Council, Ralph Bunche Road, P.O. Box 17643, Nairobi 00500, Kenya; Tel: +254-20-27।3480-3; Fax: +254-20-27|3479; E-mail: fonyango@popcouncil.org
} 


\section{Introduction}

Maternal mortality refers to deaths to women during pregnancy, childbirth or within 42 days following delivery (Hogan et al. 20l0). However, maternal deaths are mostly clustered around labour, delivery, and the immediate postpartum period (Ronsmans and Graham 2006). Maternal deaths also largely result from preventable causes including haemorrhage, hypertensive disorders, sepsis, eclampsia, HIV, obstructed labour and unsafe abortion (Goodburn and Campbell 200I; Khan et al. 2006; Ziraba et al. 2009a). Some of the most costeffective interventions to prevent maternal deaths in developing countries include the provision of antenatal care (including tetanus toxoid vaccination, screening for pre-eclampsia, as well as screening and treatment of asymptomatic bacteriuria and syphilis); skilled attendance during delivery; provision of postnatal care services; and emergency obstetric care in case of complications (Adam et al. 2005). These interventions require a well-functioning health care system that ensures that appropriate services are available, accessible, and of good quality (Goodburn and Campbell 200I). However, well-functioning health care systems are virtually non-existent in many developing countries and this has contributed to persistent high levels of maternal mortality in these regions (Goodburn and Campbell 200I; Rogo et al. 200I; World Health Organization [WHO] 20I4).

Besides a well-functioning health care system, health-seeking behaviours are also important for the prevention of maternal deaths. Studies have, for instance, shown wide socio-economic, demographic and regional variations in the use of maternal health care services in developing countries (Magadi et al. 2003, 2007; Say and Raine 2007). In Kenya, for instance, studies have found low use of maternal health services among the poor in urban areas, those living in rural areas, young women, those whose pregnancies were unintended, those with low levels of education, and those of higher parity (Fotso et al. 2008, 2009; Magadi 2004; Magadi et al. 2000, 200I; Rogo et al. 200I). Health-seeking behaviours are further shaped by a number of factors including available household resources, ineffective decisionmaking at the household level, distance to care, and perceived quality of care at health facilities (Audo et al. 2005; Essendi et al. 2010; Kyomuhendo 2003; Montagu et al. 20l I). These factors may exacerbate poor health-seeking practices especially in settings that lack proper functioning health care systems.

Studies further show that urban women in many developing countries have better access to maternal health care services and have better health indicators compared to their rural counterparts, a factor that has been attributed to greater availability of services in urban than in rural areas (Matthews et al. 2010; Ronsmans et al. 2003; Say and Raine 2007; Tawiah 20II). However, the so-called "urban advantage" masks disparities in access to maternal health care services and health outcomes within urban settings. There is a growing body of literature that shows wide disparities in maternal health care utilization and health outcomes between the urban poor and nonpoor in many developing countries (APHRC 2014; Essendi et al. 20l0; Fotso et al. 2008; Magadi et al. 2003; Magadi 2004; Ziraba et al. 2009a). In addition, studies show that the urban poor do not have better access to maternal health care despite having greater proximity to services compared to their rural counterparts (Fotso et al., 2008; Ziraba et al. 2009b). These disparities imply that maternal mortality in urban settings may be higher than what it should be if there was equitable access to services. In addition, given the greater availability of maternal health care services in such settings, it is likely that the factors contributing to maternal mortality are different compared to rural areas. There is, however, limited understanding of the factors contributing to maternal mortality in relatively resource-endowed urban settings of developing countries.

This paper examines the health-seeking and facility-level factors contributing to maternal mortality in Nairobi County of Kenya. The paper was informed by a number of factors. First, Kenya adopted a new constitution in 2010 that outlined a system of government comprising the national and county governments (Republic of Kenya 2010). With devolution, some key functions that were previously performed by the national government were transferred to counties. The devolved system of government has necessitated the need for countylevel indicators in order to inform planning and programming at the devolved units. Second, the 2009 Kenya Population and Housing Census showed that Nairobi was among the 15 counties with a high burden of maternal deaths in the country although it has historically been the most favoured in terms of allocation of resources compared to other urban or rural areas given that it is the capital city (Otiso 2005). For example, major health facilities are located in the County including public referral hospitals and private outlets. In addition, although the County is entirely urban, it is estimated that between $60 \%$ and $70 \%$ of its population live in informal settlements which are characterised by poor access to health care services (APHCR 20I4). The County therefore presents an interesting opportunity to examine factors contributing to maternal mortality given its unique setting. 


\section{Study Context}

Sub-Saharan Africa experiences the highest levels of maternal deaths compared to other developing regions of the world. As of 2013, for instance, it was estimated that the maternal mortality ratio (MMR) in the region was 510 maternal deaths per 100,000 live births, which was much higher than the levels recorded in Asia and Latin America (WHO 2014). There were, however, wide variations in maternal mortality levels in the region ranging from 73 maternal deaths per 100,000 live births in Mauritius to 1,100 maternal deaths per 100,000 live births in Sierra Leone (WHO 20I4). In Kenya, the maternal mortality ratio remained at over 400 maternal deaths per 100,000 live births during the $2000-2010$ decade (Central Bureau of Statistics [CBS] et al. 2004; Kenya National Bureau of Statistics [KNBS] and ICF Macro 20I 0; WHO 20I4).

Over the years, the Government of Kenya initiated a number of strategies aimed at improving maternal health, reducing maternal mortality and morbidity, and achieving the Millennium Development Goals (MDG) related to maternal health. For instance, the Government adapted the focused antenatal care (FANC) package that was developed by WHO with the aim of promoting interventions that address health issues of mothers and newborns (Birungi and Onyango-Ouma 2006). The Government further established the Health Sector Services Fund (HSSF) in 2005 as part of its ongoing health sector reforms to improve the delivery of essential health services by providing direct cash transfers to health facilities (Opwora et al. 2010). In 2006, the government began implementing an output-based aid reproductive health vouchers program aimed at enabling economically disadvantaged women to access essential reproductive health services (EPOS Health Management 20II; Hagenmeyer et al. 2005; PricewaterhouseCoopers 2008). In 201I, the Government initiated the performance-based finance (PBF) as one of the strategies to improve coverage and quality of health services through results-focused and motivated health workforce. In 2013, the Government abolished user fees for safe motherhood services at public health facilities (Ministry of Health 20|4).

In spite of the Government's initiatives to improve maternal health, questions remain as to why maternal mortality remained high over the years. In addition, it is likely that there are wide variations in maternal mortality between different regions of the country due to differences in socio-economic and sociocultural practices that may affect access to services and health-seeking behaviours. For instance, the importance of the major causes of maternal deaths (haemorrhage, sepsis, hypertension, eclampsia, HIV, obstructed labour and unsafe abortion) may vary by region depending on the socio-economic conditions; availability, access and quality of health services; and the prevailing health-seeking behaviours (Goodburn and Campbell 200I; Khan et al. 2006; Mills et al. 2007; Ronsmans and Graham 2006). A 2012 study in Kenya found that the number of women that were treated for complications resulting from induced abortion-one of the major causes of maternal mortality-varied from about 7,000 in Eastern to over 38,000 in the Rift Valley region of the country (Republic of Kenya 20/3).

With respect to maternal health care service utilization, available data from national and localized surveys conducted between 2008 and 2012 show that the proportion of births for which mothers made four or more antenatal care visits was lower in Nairobi County $(53 \%)$ compared to rural areas $(57 \%)$, other urban areas (58\%), the national average (57\%), and Nairobi slums (66\%; APHRC 2014; KNBS and ICF Macro 2010). However, the proportion of births for which mothers made the first antenatal care visit within the first trimester was higher in Nairobi County (22\%) compared to other urban areas (21\%), Nairobi slums (18\%), the national average (I4\%), and rural areas (I2\%; APHRC 20I4; KNBS and ICF Macro 20I0). Similarly, the proportion of births for which mothers received antenatal care from a skilled provider was higher in Nairobi County (99\%) compared to other urban areas (97\%), Nairobi slums (96\%), the national average (92\%), and rural areas (90\%; APHRC 20I4; KNBS and ICF Macro 20I0). A similar pattern existed for the proportion of births delivered in a health facility (90\% in Nairobi County, $83 \%$ in Nairobi slums, $68 \%$ in other urban areas, $43 \%$ for the national average and $36 \%$ in rural areas) and the proportion of births delivered under skilled care $(91 \%$ in Nairobi County, $83 \%$ in Nairobi slums, $69 \%$ in other urban areas, $45 \%$ for the national average, and $38 \%$ in rural areas; APHRC 20I4; KNBS and ICF Macro 20I0).

\section{Data and Methods \\ Data}

Data are from a cross-sectional study that involved a review of facility records (patient files and notes) as well as verbal and social autopsy interviews. The facility records were reviewed between March and April 2015 to capture information on the level of maternal mortality and the factors contributing to maternal deaths in the County. A total of 28 health facilities were targeted for inclusion in the study out of which 27 were randomly sampled from the master health facility list for Nairobi County. The sampling frame was health facilities that provide delivery care 
given the existing evidence that most maternal deaths occur during labour, delivery and the immediate postpartum period (Ronsmans and Graham 2006). The sampling was stratified by level of facility (hospital and health centre/maternity/nursing homes) as well as type of sector (public, private-for-profit and private-non-profit). The sample size comprised 9 hospitals ( 3 from each sector) and 18 health centres, maternity and nursing homes (6 from each sector). The sample size was purposively determined based on available health facilities that could be sampled from and the desire to obtain an equal number of facilities stratified by level from each sector. One additional public facility was purposively identified for inclusion in the study based on the fact that though located in Nairobi, it serves clients who are referred from any part of the country.

Out of the 28 facilities that were identified for inclusion in the study, one private-for-profit outlet declined to grant consent for the study while one public facility was excluded because of administrative challenges with accessing records. In each participating facility, trained research assistants obtained information on the monthly number of births and maternal deaths that occurred during the three calendar years preceding data collection (2012, 2013 and 2014). In addition, the research assistants reviewed a total of 93 records of maternal deaths that occurred at the facilities in the three years preceding data collection using a structured checklist that was adapted from the National Guidelines for Maternal and Perinatal Death Notification and Review (Ministry of Public Health and Sanitation and Ministry of Medical Services 2009).

Verbal and social autopsies were, on the other hand, conducted with a total of 7l caregivers of women who died from maternal causes aged 15-49 years to capture information on the factors contributing to maternal mortality at the community level. The interviews were conducted by research assistants with training in qualitative data collection using tools adapted from the $\mathrm{WHO}$ standard verbal and social autopsy questionnaire (WHO 20I2). 'The maternal deaths and the caregivers were purposively identified through community health units in all the I8 sub-counties of Nairobi with the help of Community Health Strategy Coordinators (CHSC) and Community Health Volunteers (CHVs). About half $(51 \%)$ of the caregivers interviewed were aged below 40 years while about three-quarters $(73 \%)$ were female. Nearly half (45\%) of the caregivers were close relatives of the deceased women (mother, spouse, sibling, son or daughter). Information was collected on the socio-demographic characteristics of the deceased; essential elements of care-seeking process such as recognition of symptoms and signs associated with illness; whether adequate care was provided; whether and what type of outside-the-home care was sought (informal, formal, or both), cause and place of death. The interviews were audio-recorded with the consent of participants.

The Institutional Review Board (IRB) of the Population Council (Protocol number 679) and the Ethics and Research Committee of Kenyatta National Hospital/University of Nairobi (Protocol number P62/02/2015) granted ethical approval for the study while the National Commission for Science, Technology and Innovation (NACOSTI) granted the research permit (Reference number NACOSTI/P/I5/6280/5260). In addition, written informed consent was obtained from health facility in-charges and caregivers before conducting record reviews and interviews respectively. The interviews with caregivers were conducted in Kiswahili or English depending on the preference of informants.

\section{Analysis}

Analysis of quantitative data from record reviews and verbal autopsies was conducted using Stata ${ }^{\circledR}$ and involved computing frequencies and percentages. Verbal autopsy data were first coded by two people with medical training using the International Classification of Disease (ICD)-I0 to determine the causes of maternal deaths based on caregivers' descriptions. In cases where the coders did not agree on the cause of death, they sought consensus among themselves. There were no cases where the coders did not agree on the cause of death. Social autopsy data were, on the other hand, transcribed, typed in Word, translated into English for interviews conducted in Kiswahili and analysed for content. Analysis entailed identifying patterns across caregivers' narratives regarding the causes of deaths and care-seeking behaviours during the period prior to the deaths.

\section{Results}

\section{Characteristics of deceased women}

Findings from facility records and verbal autopsies showed that in both cases, the majority of maternal deaths occurred to women aged $20-29$ years (57\% and $49 \%$ of cases from facility records and verbal autopsies respectively; Table I). Both sources of data further showed that the highest proportion of maternal deaths occurred to women with primary or lower levels of education (38\% and $56 \%$ of cases from facility records and verbal autopsies respectively). Most of the women were married or living with a man at the time of death $(63 \%$ and $54 \%$ of cases from facility records and verbal autopsies respectively). In addition, although most of the 
women were young at the time of death, a substantial proportion had given birth at least twice (51\% and $45 \%$ of cases from facility records and verbal autopsies respectively).

Table I: Percent distribution of deceased women by background characteristics and data source

\begin{tabular}{|c|c|c|}
\hline Characteristics & $\begin{array}{r}\text { Facility records } \\
\qquad(\mathrm{N}=93)\end{array}$ & $\begin{array}{r}\text { Verbal autopsies } \\
\qquad(\mathrm{N}=7 \mathrm{I})\end{array}$ \\
\hline \multicolumn{3}{|l|}{ Age group (years) } \\
\hline$<20$ years & 6.5 & 18.3 \\
\hline $20-24$ & 21.5 & 29.6 \\
\hline $25-29$ & 35.5 & 19.7 \\
\hline $30-34$ & 18.3 & 9.9 \\
\hline 35 and above & 16.1 & 18.3 \\
\hline Don't know/missing & 2.2 & 4.2 \\
\hline \multicolumn{3}{|l|}{ Education level } \\
\hline Primary or lower & 37.6 & 55.7 \\
\hline Secondary and above & 32.3 & 41.4 \\
\hline Don't know/missing & 30.1 & 2.9 \\
\hline \multicolumn{3}{|l|}{ Marital status } \\
\hline Never married & 23.7 & 29.6 \\
\hline Married/living together & 63.4 & 53.5 \\
\hline Divorced/separated/widowed & I.I & 17.9 \\
\hline Don't know/missing & 11.8 & 0.0 \\
\hline \multicolumn{3}{|l|}{ Parity } \\
\hline 0 & 17.2 & 32.4 \\
\hline 1 & 28.0 & 22.5 \\
\hline 2 & 25.8 & 18.3 \\
\hline 3 and above & 24.7 & 26.8 \\
\hline Don't know/missing & 4.3 & 0.0 \\
\hline All women & 100.0 & 100.0 \\
\hline
\end{tabular}

Source: Facility records and verbal autopsies.

The results in Table I further show that the proportion of mothers who died aged below 20 years was more than two times higher among those identified in the community than in the facility $(18 \%$ compared to $7 \%$ of cases). Similarly, the proportion of those who were never married at the time of death was higher among those identified in the community than in the facility $(30 \%$ and $24 \%$ of cases respectively). A similar pattern was noted for the proportion of deceased women who had never previously given birth, which was nearly twice as high among those identified in the community compared to those identified in the facility $(32 \%$ and $17 \%$ of cases respectively).

\section{Direct and indirect causes of maternal deaths}

Data from facility records showed that the most common direct causes of maternal deaths in the County were infection (29\%), preeclampsia/eclampsia (23\%), haemorrhage (22\%), and abortion (I8\%; Figure I). Obstructed labour was less common accounting for $4 \%$ of maternal deaths while other causes included embolism, bipedal oedema, ectopic pregnancy, and placenta abruption altogether contributing to $17 \%$ of the deaths. The most common indirect causes of maternal deaths included cardiovascular conditions (42\%), anaemia (26\%), and HIV/AIDS (I8\%; Figure 2). Other indirect causes included kidney failure, meningitis, puerperal psychosis and pulmonary tuberculosis altogether contributing to $32 \%$ of the deaths. 
Figures I and 2: Direct and indirect causes of maternal mortality in Nairobi County

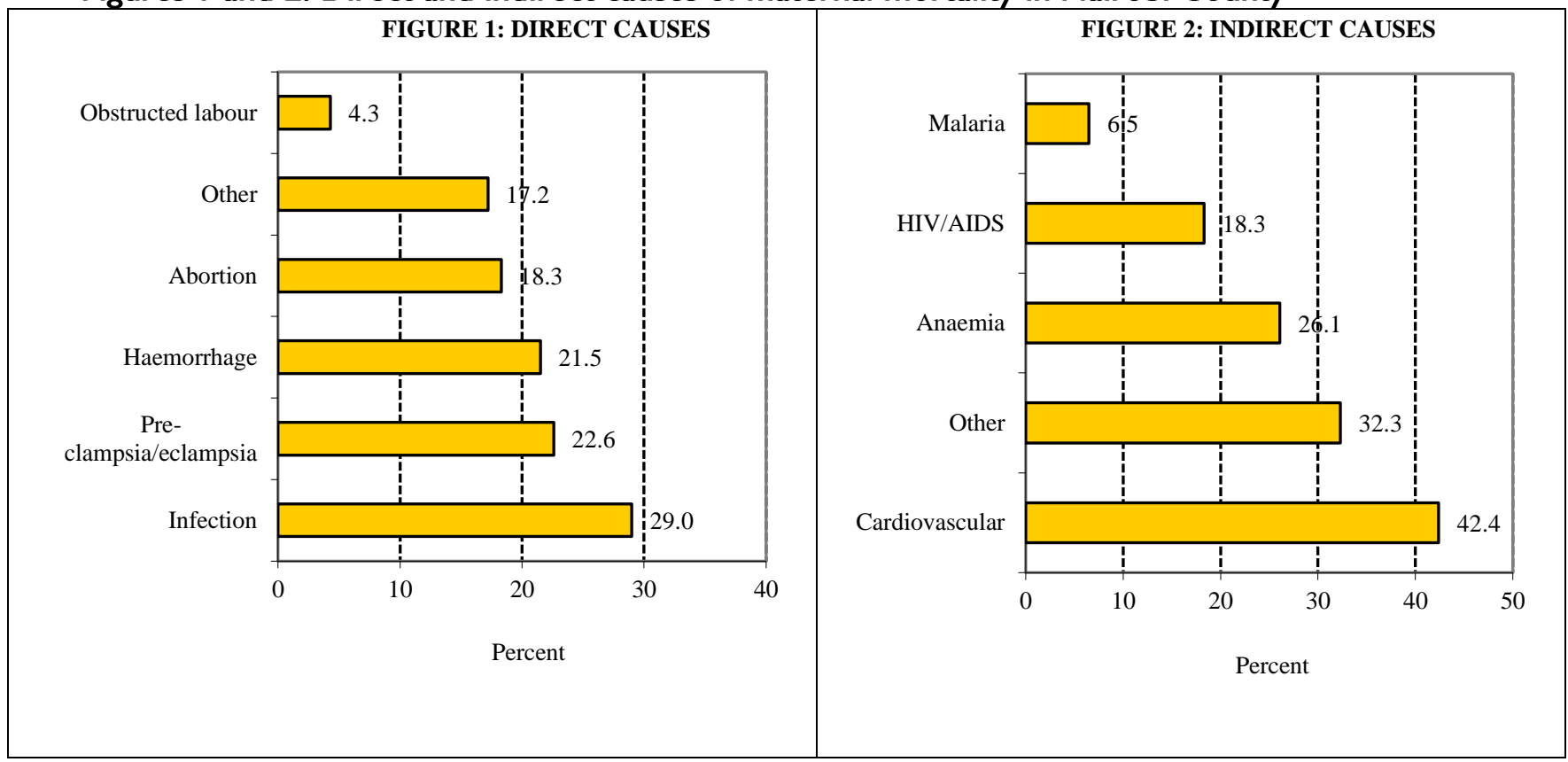

Source: Facility records.

Data from verbal and social autopsies showed that the most common direct causes of maternal deaths were similar to those identified from facility records although of varying degree. These included haemorrhage ( $41 \%$ of the cases), infection (16\% of the cases), and abortion ( $9 \%$ of the cases) while preeclampsia/eclampsia and obstructed labour each accounted for $3 \%$ of the cases (not shown). The most common indirect causes identified from the community, on the other hand, included anaemia and HIV/AIDS accounting for $14 \%$ and $7 \%$ of the cases respectively while cardiovascular conditions accounted for $4 \%$ of the deaths (not shown).

\section{Health-seeking behaviours of deceased women}

Among the maternal deaths identified from facility records, more than half $(53 \%)$ of the deceased women sought antenatal care, $18 \%$ did not while information was missing for the remainder of the cases (not shown). Slightly more than a third (35\%) of the deceased women who sought any antenatal care made less than four visits, a third (33\%) made four or more visits while information was missing for another $33 \%$. Verbal autopsy interviews with caregivers of women who died from maternal-related causes, on the other hand, showed that $68 \%$ of the women received treatment for the illness that led to death, $20 \%$ did not while the remaining informants did not know whether treatment was received. In addition, $9 \%$ of the caregivers reported that the deceased women used traditional medicine (not shown). Findings from social autopsy interviews indicated that some of the maternal deaths were due to poor health-seeking behaviours of the deceased including not seeking antenatal or delivery care from qualified personnel as exemplified by the following excerpts:

Yes [she was the one who refused to go to hospital] and she was a difficult person to reason with. When you enquired if she was okay, she used to say she was not very ill and when you give her directions to where she would be assisted, she used to come back and say that she did not have the money to pay the bills but I think she refused to deliver in the hospital because she had not been attending the [antenatal care] clinic (Female, 39 years old, neighbour to deceased).

On the first day she did not tell me the truth but said she had malaria. On the second day is when I noticed she was bleeding. I insisted to know the truth and she said she had gone to [name of place] and someone inserted a tube inside her vagina as she was pregnant and wanted to abort. When the tube was inserted she was told to go home and the abortion will take place. When that didn't work she bought some medicine and overdosed ... The following day she got worse and we took her to the nearest private health facility where she was put on drip and we were given a note and told to go to [name of] hospital. While on the way the abortion took place, she bled a lot and died before arrival at the hospital (Male, 3 I years old, neighbour to deceased).

\section{Delays in seeking and receiving care}

Data from facility records showed that nearly threequarters $(7 \mid \%)$ of the cases were in critical condition at the time of admission indicating delays in seeking care (not shown). In addition, at the household/family level (first delay), the most common factors 
contributing to maternal mortality included failure to recognize danger signs (44\%), poverty (40\%), high cost of treatment (29\%), and ignorance of available services (14\%; Table 2). Other factors included unspecified delay in seeking care, non-adherence to antiretroviral treatment, and failure to take up referral to higher level facility altogether contributing to $13 \%$ of the deaths. Lack of communication/ transport between health facilities was the most common factor contributing to delay in accessing skilled care beyond the household/family level (second delay) accounting for $15 \%$ of the maternal deaths while lack of communication/transport from home to health facility or long distances/poor roads accounted for $7 \%$ of maternal deaths each (Table 2). At the health facility level (third delay), poor provider attitudes, low morale or poor interpersonal relationships and lack of skilled human resources were the two most common factors contributing to maternal deaths (44\% and $26 \%$ respectively). Other factors included lack of intensive care unit (ICU) facilities, lack of computerized tomography (CT) scan, and work load altogether accounting for 15\% of the deaths (Table 2).

Table 2: Distribution of maternal deaths according to delays in seeking and receiving care

Indicator

Percent

$(\mathrm{N}=93)$

First delay: household/family level

Failure to recognize danger signs

Poverty

High cost of treatment

Ignorance of available services

Other

Cultural/religious reasons/objections

Second delay: between household and facility

Lack of communication/transport between facilities

Lack of communication/transport from home

Long distances/poor roads

Other

Third delay: at health facility

Poor provider attitudes/low morale

Lack of skilled human resources

Other

Lack of blood transfusion

Lack of expertise

Lack of skills

Source: Facility records; Note: Questions allowed for multiple options.

Availability of adequate resources emerged from the verbal autopsies as a major barrier to seeking quality care. Nearly two-thirds (61\%) of the caregivers reported that there was lack of adequate financial resources to allow for seeking quality care during illness (not shown). More than half (56\%) of the caregivers reported that additional financial resources would have made a difference in the outcome of the illness while $55 \%$ indicated that the cost of care prohibited other household payments (not shown). Social autopsy interviews further showed that lack of adequate financial resources hampered seeking appropriate care as shown by the following quotes:

We did not have enough money but if we did, things would have been different. You know, she started feeling pain but would just stay quiet ... We took her to the herbalist so that she could massage her stomach, but would have taken her to a better facility if we had money (Female, 38 years old, other relative to deceased).

When she was in labour, we took some time trying to raise money for paying for the means of transport that was to be used to take her to hospital and her condition continued to get worse (Female, 44 years old, other relative to deceased).

Besides availability of adequate resources, findings from social autopsy interviews showed that inability to recognize danger signs at the household/family level and thus seek timely care also contributed to maternal deaths as the following quotes indicate:

She was very close to me such that she could tell me everything. She started complaining of her neck. It went on for two days and then she told me headache had started. This was followed by nose 
bleeding. It was then I took her to the hospital and upon examination, I was told she was suffering from meningitis which had advanced. I was told that I should have taken her early enough (Male, 29 years old, sibling to deceased).

Even the time she had started feeling sick they would have taken immediate action and taken her to hospital. The elderly people who were with her just thought it was the normal one, so when she started saying that she was dying that is when they would have taken action even before her starting to vomit blood. If she had vomited while at the hospital she would have been given the help that was needed (Female, 53 years old, mother to deceased).

Some caregivers further reported during social autopsy interviews that there were delays with respect to referrals (second delay). A key theme emerging from the narratives was that the deceased and their caregivers first sought care at nearby mostly private clinics. However, the caregivers realized that the quality of care at such clinics was wanting. They then experienced difficulties securing referrals to higher level facilities either due to nonresponsiveness by providers at the clinics where the patients were first admitted or lack of means of transport to the referral facility. The following quotes highlight these experiences:

It was a forced referral. After delivery the doctor just kept her there despite her deteriorating condition. He was just giving her injections. The husband was called and on reaching there he found the wife had bled a lot. He took his wife from the clinic by force and took her to [name of hospital]. The clinic doctor was forced to write a referral letter to [name of hospital] (Female, 36 years old, other relative to deceased).

She was received and they checked her condition before referring her to [name of hospital] but there was a problem with the ambulance ... They were saying there was no ambulance (Male, 36 years old, sibling to deceased).

Other caregivers reported that mothers died because of poor quality of care at health facilities where they were admitted (third delay). The narratives suggested that poor quality of care was characterized by lack of expertise/skills to identify high-risk deliveries, poor provider attitudes, lack of adequate human resources, long waiting times, and lack of blood for transfusion. The following excerpts highlight some of these challenges:

Those who were near where [name of patient] was admitted told us that she delivered well and was brought to the bed with her child but after a while she started experiencing pain and was taken back to the theatre where she delivered the second child but didn't come back. They had not identified she was expecting twins (Female, 43 years old, neighbour to deceased).

We went together to [name of facility] and she was taken straight to labour ward. I called her husband and told him to follow us to [name of facility]. It was late in the evening so she was admitted and we left. She stayed in hospital before giving birth and on the fourth day I visited her since she had requested that I take to her some cooked bananas and potatoes. When I got there ... she had given birth on her own, no health provider to assist her. She was still on the floor with the baby and the baby was dead. She had bled a lot and was on the floor, weak with eyes looking up. The other patients said the doctors didn't assist her and that she suffered a lot (Female, 39 years old, other relative to deceased).

\section{Discussion}

The major finding of this paper is that maternal deaths in Nairobi County are largely due to poor health-seeking behaviour on the part of the deceased women, delays at the household level in seeking care, poor referral mechanisms, poor provider attitudes, and lack of skilled human resources. Poor healthseeking behaviour was characterised by not seeking professional care at all or seeking care from unqualified personnel. Delays at the household level were, on the other hand, due to failure to recognize danger signs early, poverty, high cost of treatment, and ignorance of available services. Ideally, poverty should not be a major barrier to seeking care following the introduction of free maternity services in the public sector in June 2013 (Ministry of Health 20I4). However, the findings of this paper showed that individuals still needed money to cover transport costs to health facilities. Although distance to health facilities did not emerge as a major contributor to maternal mortality in the County, the need for transport could be due to the tendency to seek care when it was too late with a high proportion of women being admitted in health facilities in critical conditions. Poor health-seeking behaviour and delays in seeking care at the household/family level suggest that programs aimed at improving maternal health in the County should focus on empowering households to appreciate the importance of professional care and to recognize danger signs early.

Beyond the household/family level, poor referral mechanisms were either due to lacklustre response from providers in lower level facilities where the deceased women first sought care or lack of means of transport to the referral facilities. Available evidence indicates that lack of proper referral linkages between health facilities affects the uptake of services even in the presence of subsidies such as use 
of vouchers to access care (Njuki et al. 20I2). The implication is that even with free maternity services, mothers in the County are likely to continue dying if there are no proper referral linkages between lower level facilities where most women first seek care and higher level ones which are better equipped to handle maternal-related complications. In the public sector, poor provider attitudes and lack of skilled human resources could largely be due to high workload against the backdrop of limited financial and human resources (Saksena et al. 20I2). In the private sector, the issue could be about limited availability of personnel with appropriate technical skills (Brugha and Zwi 1998). Regardless of the circumstances, delays in providing appropriate care that occur between and within health facilities in the County suggest the need for improving referral linkages and enhancing the capacity of providers to offer quality services through skills updates and ensuring adequate maternal health supplies.

Another finding of the paper is that most maternal deaths in the County occurred to women who were young, married, with low levels of education and those that had at least two births. The finding is consistent with existing literature that indicates that without appropriate care, pregnancies to young women can have adverse outcomes which can result in long-term morbidity or even death (Becher et al. 2004; Reynolds et al. 2006). Moreover, higher proportions of deaths among very young women (aged below 20 years), those who had never married, and those who had not previously given birth were identified in the community than in the facilities. This could be an indication that most deaths to adolescent mothers (aged below 20 years and unlikely to have ever married or previously given birth) could be occurring outside of health facilities. Studies show that young people's access to sexual and reproductive health services in developing countries is affected by several factors including contradictory socio-cultural norms in some communities that on the one hand promote early marriage and on the other discourage adolescent sexuality and early pregnancy; weak health care systems; and reproductive health services that are in most cases not oriented towards adequately meeting their needs (Katz and Naré 2002; Tylee et al. 2007; Varga 2003; Warenius et al. 2006; Wood and Jewkes 2006; Wright et al. 2006). Improving young people's access to health care services therefore requires interventions at the individual, household and provider levels.

The above findings might be influenced by the limitations of the study that provided the data used in the paper. The first limitation is the incompleteness of information obtained from facility records. This was evident from the proportion of cases with missing information on some of the sociodemographic characteristics and health-seeking behaviours of deceased women. Completeness of mortality data is a major challenge facing many developing countries where there are no comprehensive systems of registering deaths and ascertaining the causes (Hill et al. 2006). The implication is that factors associated with maternal mortality might be grossly under-estimated. The second limitation is that depending on how far back deaths occurred, information from verbal and social autopsies might be affected by recall bias or the nature of the relationship of the caregiver to the deceased. Information obtained soon after death occurrence from close family members may, for instance, be more reliable compared to that gathered long after death from individuals who are not related to the deceased. However, conducting verbal and social autopsies soon after death occurrence may not be ethically appropriate as this may be insensitive to the feelings of affected persons. Third, the study was limited to Nairobi County; the findings might not be generalizable to all urban areas or rural settings of the country. In spite of these limitations, the findings of the paper provide some indications of the factors that contribute to maternal mortality in a relatively resource-endowed urban context.

\section{Notes}

Verbal autopsy is a research method that helps determine probable causes of death in cases where there is no medical record or formal medical attention given and involves conducting interviews with next of kin or other caregivers (WHO 20I2). Social autopsy, on the other hand, refers to an interview process with a next of kin or other caregivers of deceased individuals aimed at identifying social, behavioural, and health systems contributors to deaths in the community (Kalter et al. 20I I). Both verbal and social autopsies provide information that informs the design and implementation of initiatives aimed at improving maternal and child health (Kalter et al. 20I I; WHO 20I2).

\section{Acknowledgement}

The study that provided the data for this paper was funded by the United Nations Population Fund (UNFPA) Kenya Country Office through an Implementing Partner Agreement (IPA) with the Population Council. The study was implemented by the Population Council in collaboration with the Nairobi City County Health Services (NCCHS). The Institutional Review Board of the Population Council and the Ethics and Research Committee of Kenyatta National Hospital/University of Nairobi granted 
ethical approval for the study while the National Commission for Science, Technology and Innovation (NACOSTI) granted the research permit. The opinions expressed in the paper are, however, those of the authors and do not necessarily reflect the views of the funding or implementing agencies.

\section{References}

Adam, T., Lim, S.S., Mehta, S., Bhutta, Z.A., Fogstad, H., Mathai, M., Zupan, J. and Darmstadt, G.L. 2005. "Achieving the millennium development goals for health: cost-effectiveness analysis of strategies for maternal and neonatal health in developing countries." BM/ 33 I ( | | 07): I-6.

APHRC (African Population and Health Research Center). 2014. Population and Health Dynamics in Nairobi's Informal Settlements: Report of the Nairobi Cross-sectional Slums Survey (NCSS) 20/2. Nairobi: APHRC.

Audo, M.O., Ferguson, A. and Njoroge, P.K. 2005. "Quality of health care and its effects in the utilisation of maternal and child health services in Kenya." East African Medical Journal 82(I I):547553.

Becher, H., Müller, O., Jahn, A., Gbangou, A., KynastWolf, G. and Kouyaté, B. 2004. "Risk factors of infant and child mortality in rural Burkina Faso." Bulletin of the World Health Organization 82(4):265-273.

Birungi, H. and Onyango-Ouma, W. 2006. Acceptability and sustainability of the WHO focused antenatal care package in Kenya. Nairobi: Population Council.

Brugha, R. and Zwi, A. 1998. "Improving the quality of private sector delivery of public health services: challenges and strategies." Health Policy and Planning |3(2): I07-I 20.

Central Bureau of Statistics (CBS) [Kenya], Ministry of Health (MOH) [Kenya], and ORC Macro. 2004. Kenya Demographic and Health Survey 2003. Calverton, Maryland: CBS, $\mathrm{MOH}$, and ORC Macro.

EPOS Health Management. 20II. Mid Term Review of the 'Development of the Health Sector (SWAP) Programme - Reproductive Health Voucher Scheme (Output Based Approach) in Kenya'. BadHomburg, Germany: EPOS Health Management.

Essendi, H., Mills, A. and Fotso, J.C. 20I0. "Barriers to formal emergency obstetric care services' utilization." Journal of Urban Health 88(suppl. 2):S356-S369.

Fotso, J.C., Ezeh, A., Madise, N., Ziraba, A. and Ogollah, R. 2009. "What does access to maternal care mean among the urban poor? Factors associated with use of appropriate maternal health services in the slum settlements of Nairobi, Kenya." Maternal and Child Health Journal I3(I): I30-137.

Fotso, J.C., Ezeh, A. and Oronje, R. 2008. "Provision and use of maternal health services among urban poor women in Kenya: what do we know and what can we do?" Journal of Urban Health 85(3):428-44I.

Goodburn, E. and Campbell, O. 200I. "Reducing maternal mortality in the developing world: sector-wide approaches may be the key." BMJ 322:917-920.

Hagenmeyer, E.G., Griffin, D., Ahmed, R., Teshome, E., Barsch, A., Muga, R. and Haussler, B. 2005. Design study for output-based assistance programme Kenya: final report. Berlin: IGES Paper 05-67.

Hill, K., El-Arifeen, S, Koenig, M., Al-Shabir, A., Jamil, K. and Raggers, H. 2006. "How should we measure maternal mortality in the developing world? A comparison of household deaths and sibling history approaches." Bulletin of the World Health Organization 84(3): I 73- I80.

Hogan, M.C., Foreman, K.J., Naghavi, M., Ahn, S.Y., Wang, M., Makela, S.M., Lopez, A.D., Lozano, R. and Murray, C.J.L. 20I0. "Maternal mortality for I8I countries, 1980-2008: a systematic analysis of progress towards Millennium Development Goal 5." Lancet 375(9726): 1609-1623.

Katz, K. and Naré, C. 2002. "Reproductive health knowledge and use of services among young adults in Dakar, Senegal." Journal of Biosocial Science 34(2):2I5-23I.

Kalter, H.D., Salgado, R., Babille, M., Koffi, A.K. and Black, R.E. 20I I. "Social autopsy for maternal and child deaths: a comprehensive literature review to examine the concept and the development of the method." Population Health Metrics 9(45): I-I 3.

Kenya National Bureau of Statistics (KNBS) and ICF Macro. 2010. Kenya Demographic and Health Survey 2008-2009. Calverton, Maryland: KNBS and ICF Macro.

Khan, K.S., Wojdyla, D., Say, L., Gülmezoglu, A.M. and van Look, P.F.A. 2006. "WHO analysis of causes of maternal death: a systematic review." Lancet 367(95I6): 1066-1074.

Kyomuhendo, G.B. 2003. "Low use of maternity services in Uganda: impact of women's status, traditional beliefs and limited resources." Reproductive Health Matters I I (2 I): I6-26.

Magadi, M., Agwanda, A. and Obare, F. 2007. "A comparative analysis of the use of maternal health services between teenagers and older mothers in sub-Saharan Africa: evidence from Demographic and Health Surveys (DHS)." Social Science \& Medicine 64(6): | 3 | |-| 325. 
Magadi, M. 2004. "Maternal and child health among the urban poor in Nairobi, Kenya." African Population Studies 19(suppl. B): I7I-190.

Magadi, M. A., Zulu, E.M. and Brockerhoff, M. 2003. "The inequality of maternal health care in urban sub-Saharan Africa." Population Studies 57(3):347366.

Magadi, M., Diamond, I. and Madise, N. 200I. "Analysis of factors associated with maternal mortality in Kenyan hospitals." Journal of Biosocial Science 33(3):375-389.

Magadi, M.A., Madise, N.J. and Rodrigues, R.N. 2000. "Frequency and timing of antenatal care in Kenya: explaining the variations between women of different communities." Social Science \& Medicine 5I(4):55I-56I.

Matthews, Z., Channon, A., Neal, A., Osrin, D., Madise, N. and Stones, W. 2010. "Examining the 'urban advantage' in maternal health care in developing countries." PLOS Medicine 7(9): I-7.

Mills, S., Bos, E., Lule, E., Ramana, G.N.V. and Bulatao, R. 2007. Obstetric care in poor settings in Ghana, India, and Kenya. HNP Discussion Paper. Washington, DC: World Bank.

Ministry of Health [Kenya]. 20I4. Free Maternity Services. Government Circular ACC/FMHS/I/28A of April 20I4. Nairobi: Ministry of Health.

Ministry of Public Health and Sanitation (MOPHS) and Ministry of Medical Services (MOMS) [Kenya]. 2009. National Guidelines for Maternal and Perinatal Death Notification and Review. Nairobi: MOPHS and MOMS.

Montagu, D., Yamey, G., Visconti, A., Harding, A. and Yoong, J. 20II. "Where do poor women in developing countries give birth? A multi-country analysis of Demographic and Health Survey data." PLoS One 6(2): I-8.

Njuki, R., Okal, J., Warren, C.E., Obare, F., Abuya, T., Kanya, L., Undie, C.C., Bellows, B. and Askew, I. 2012. "Exploring the effectiveness of the output-based aid voucher program to increase uptake of gender-based violence recovery services in Kenya: a qualitative evaluation." $B M C$ Public Health I2(426): I-7.

Opwora, A., Kabare, M., Molyneux, S. and Goodman, C. 2010. "Direct facility funding as a response to user fee reduction: implementation and perceived impact among Kenyan health centres and dispensaries." Health Policy and Planning 25(2):406-4I8.

Otiso, K.M. 2005. "Kenya's secondary cities growth strategy at crossroads: which way forward?" Geo Journal 62(I-2): I I 7-I 28.

PricewaterhouseCoopers. 2008. Reproductive Health Output-Based Aid: End of Pilot Project Report. Vol. I. Nairobi: PricewaterhouseCoopers.
Republic of Kenya. 2013. Incidence and complications of unsafe abortion in Kenya: Key findings of a national study. Nairobi: African Population and Health Research Center, Ministry of Health, Kenya, Ipas, and Guttmacher Institute.

Republic of Kenya. 20I0. Constitution of Kenya 2010. Nairobi: Republic of Kenya.

Reynolds, H.W., Wong, E.L. and Tucker, H. 2006. "Adolescents' use of maternal and child health services in developing countries." International Family Planning Perspectives 32(I):6-16.

Rogo, K.O., Aloo-Obunga, C., Ombaka, C., Oguttu, M., Orero, S., Oyoo, C. and Odera, J. 200I. "Maternal mortality in Kenya: the state of health facilities in a rural district." East African Medical Journal 78(9):468-472.

Ronsmans, C. and Graham W.J. on behalf of The Lancet Maternal Survival Series steering group. 2006. "Maternal mortality: who, when, where and why." Lancet 368(9542): I I89-I 200.

Ronsmans, C., Etard, J.F., Walraven, G., Hødj, L., Dumont, A., de Bernis, L. and Kodio, B. 2003. "Maternal mortality and access to obstetric services in West Africa." Tropical Medicine and International Health 8( I0):940-948.

Saksena, P., Xu, K., Elovainio, R. and Perrot, J. 2012. "Utilization and expenditure at public and private facilities in 39 low-income countries." Tropical Medicine \& International Health I 7(I):23-25.

Say, L. and Raine, R. 2007. "A systematic review of inequalities in the use of maternal health care in developing countries: examining the scale of the problem and the importance of context." Bulletin of the World Health Organization 85(I0):8| 2-8I9.

Tawiah, E.O. 20I I. "Maternal health care in five subSaharan African countries." African Population Studies 25(I):I-25.

Tylee, A., Haller, D.M., Graham, T., Churchill, R., and Sanci, L.A. 2007. "Youth-friendly primarycare services: how are we doing and what more needs to be done?" Lancet 369(9572): I565-I573.

Varga, C.A. 2003. "How gender roles influence sexual and reproductive health among South African adolescents." Studies in Family Planning 34(3): 160-I 72.

Warenius, L.U., Faxelid, E.A., Chishimba, P.N., Musandu, J.O., Ong'any, A.A. and Nissen, E.B.M. 2006. 'Nurse-midwives' attitudes towards adolescent sexual and reproductive health needs in Kenya and Zambia." Reproductive Health Matters I4(27): I I9- I 28.

Wood, K. and Jewkes, R. 2006. "Blood blockages and scolding nurses: barriers to adolescent 
contraceptive use in South Africa." Reproductive Health Matters 14(27): 109-1 I8.

WHO (World Health Organization). 2014. Trends in Maternal Mortality: 1990 to 2013. Geneva: WHO.

WHO (World Health Organization). 20I2. Verbal Autopsy Standards: the 2012 WHO Verbal Autopsy Instrument Release Candidate I. Geneva: WHO.

Wright, D., Plummer, M.L., Mshana, G., Wamoyi, J., Shigongo, Z.S. and Ross, D.A. 2006. "Contradictory sexual norms and expectations for young people in rural Northern Tanzania." Social Science \& Medicine 62(4):987-997.

Ziraba, A.K., Madise, N., Mills, S., Kyobitungi, C. and Ezeh, A. 2009a. "Maternal mortality in the informal settlements of Nairobi city: what do we know?" Reproductive Health 6(6): I-8.

Ziraba, A.K., Mills, S., Madise, N., Saliku, T. and Fotso, J.C. 2009b. "The state of emergency obstetric care services in Nairobi informal settlements and environs: results from a maternity health facility survey." BMC Health Services Research 9(46): I-8. 